\title{
Relationship between Representative Anthropometric Dimensions and Income Levels for Korean
}

\author{
Dohyung Kee \\ Department of Industrial and Management Engineering, Keimyung University, Taegu, 704-701
}

\begin{abstract}
Objective: This study aims to investigate relationship between representative anthropometric dimensions and income levels for Korean from 1958 to 1989. The anthropometric dimensions include stature and body weight, and GNP per head was used as an index of income level. Background: Although anthropometric dimensions were affected by varying factors such as genetic, environmental and socioeconomic factors, most studies on anthropometry have focused on measurement methods, providing data and their characteristics. Method: Anthropometric data were retrieved from homepages of Korean Agency for Technology and Standards, and Ministry of Culture, Sports \& Tourism, and GNPs per head by year from Korean Statistical Information Service. Results: During analysis period, statures and body weights for males and females increased by $6.4 \mathrm{~cm}$ and $6.1 \mathrm{~cm}, 10.7 \mathrm{~kg}$ and $4.0 \mathrm{~kg}$, respectively. Infants' stature and body weight nearly linearly increased with GNPs per head. Anthropometric dimensions of stature and body weight were very positively correlated with GNPs per head. Conclusion: This study revealed that income levels significantly affect stature and body weight. Application: The results would be used as a valuable basic data when establishing government policies related to anthropometry.
\end{abstract}

Keywords: Anthropometry, Income level, GNP, Correlation, Socioeconomics

\section{Introduction}

국가 간 및 기업 간 경쟁이 극심해지면서 제품 디자인의 중요성이 더해지고 있다. 좋은 제품을 디자인하기 위해서 가 장 기본적으로 고려되어야 할 요소 중의 하나가 인체 측정치 의 활용이다. 인체 측정 자료를 마련하기 위하여 세계 주요 국가에서는 국가적 사업으로 인체 측정을 수행하여 오고 있 다. 우리나라도 1979년부터 현재까지 6차례 전국적인 인체 측정 사업을 시행하였다(Kee et al., 2011).

우리나라에서의 인체 측정에 관한 연구는 인체 측정치 현 황, 치수 간의 관계, 연령 및 성별 특성 등에 초점이 맞추어 져 왔다. Kim et al. (1989) 과 $\mathrm{YoO}(2006)$ 는 인체 측정 조사 사업을 바탕으로 성별 및 연령대별 한국인의 신체 특성을 조 사하였다. Jung(1998) 은 고등학교 3학년 540명의 건강기
록부를 조사하여 신장의 성장 특성을 분석하는 종단적 연구 (longitudinal) 연구를 수행하였다. Jung and Lee(2001)는 60 대 이상 고령층의 발 치수 49 개 항목을 측정하여, 이를 바탕으로 발 형태를 분류하고 고령층 신발 호수 체계를 설정 하였다.

인체 측정치는 연령, 성별과 같은 인구통계학적 변수뿐만 아니라 다양한 요인의 영향을 받는 것으로 알려져 있다. 신 장은 3 가지 요인 즉, 유전적 요인, 환경적 요인, 사회경제학 적 요인에 크게 영향을 받는 것으로 알려져 있다(Tanner, 1978). 따라서 인체 측정치의 바른 이해를 위해서는 인체 측정치와 다양한 요인과의 관계에 대한 연구가 필요하다. 인 구통계학적 요인 외의 영향을 밝히는 연구로 Choi(2006)는 한국인의 신장 변화와 생활 수준 간의 관계를 다루었다. 이 연구는 식민지 세대의 신장 자료를 중심으로 연구가 이루어 져 경제가 비약적으로 발전한 현재 상황에 적용하기에는 무

Corresponding Author: Dohyung Kee. Department of Industrial and Management Engineering, Keimyung University, Taegu, $704-701$.

Mobile: 010-5656-1260, E-mail: dhkee@kmu.ac.kr

Copyright@2012 by Ergonomics Society of Korea(pISSN:1229-1684 eISSN:2093-8462). All right reserved. 
리가 있다.

본 연구에서는 경제 성장기인 1960년대 1980년대 한국 인의 인체 측정치와 사회경제적 요인과의 관계를 분석하고 자 한다. 이를 위하여 대표적 인체 측정치인 신장 및 체중과 소득 수준을 나타내는 대표적 지수인 일인당 GNP와의 관계 를 분석한다. 본 연구의 결과는 소득 수준에 따른 인체 측정 치의 전반적 경향을 이해할 수 있는 자료가 될 수 있을 것으 로 기대된다.

\section{Method}

\subsection{Age group}

본 연구에서는 신체적 발육이 종료되는 시점으로 알려져 있는 20대(자료 출처에 따라 19 24세, 20 21세, 20 24세, 21 25세, 22 24세) 의 인체 측정치 즉, 신장과 체중 자료를 사용하였다. 이는 남녀 모두 20대 전반에 키가 다 자란다는 Yoo(2006)의 연구에 근거한 것이다. 영아의 신장 및 체중 과 소득 수준 간의 관계 분석에는 참조한 자료에서 최소 연 령대인 0 2개월 연령대의 자료를 사용하였다.

\subsection{Data gathering}

본 연구에 사용된 신장과 체중 자료는 1979년부터 2004 년까지 기술표준원에서 5차례(1차: 1979년; 2차: 1985년; 3차: 1991년; 4차: 1996년; 5차: 2003 2004년) 실시한 국가적 인체 측정 사업의 차수별 인체치수조사 사업보고서 자료를 기본으로 하였다(Size Korea Home Page, 2011). 이와 더불어 문화체육관광부의 1989 2009년까지의 신장 및 체중 변화 자료 중 19 24세 연령대 자료를 사용하였다 (KOSIS Home page, 2011). 본 연구에서는 다음의 관점에 서 인체 측정치를 20 대 초반 자료로 제한하였다. 첫째, 앞서 언급한 바와 같이 $\mathrm{YoO}(2006)$ 는 20대 초반에 신장의 성장 이 완료된다고 보고하였다. 둘째, Kroemer et al.(1994)에 의하면 추간판, 추골(vertebrae), 연골의 평편화, 등뼈의 굴 곡 변화 등으로 30 대부터 나이가 들어감에 따라 매 10년 마 다 신장이 약 $1.0 \mathrm{~cm}$ 감소한다. 이러한 연령의 영향은 개인 에 따라 다를 가능성이 높으므로 30 대 이후의 신장은 객관 적 자료로 적절하지 않다.

소득 수준을 나타내는 지수인 일인당 $\mathrm{GNP}$ 는 국가통계포 털 홈페이지로부터 구하였다(KOSIS Home page, 2011). 소득 자료는 본 연구에서 인용한 인체 측정치에 해당하는 연

Table 1. Data used in this study

\begin{tabular}{|c|c|c|c|c|c|c|c|c|}
\hline \multirow{2}{*}{ Data source } & \multicolumn{2}{|c|}{ Age(year) } & \multicolumn{2}{|c|}{ Stature $(\mathrm{cm})$} & \multicolumn{2}{|c|}{ Weight(kg) } & \multirow{2}{*}{ Year of birth } & \multirow{2}{*}{$\begin{array}{c}\text { GNP per head } \\
(10,000 \text { won })\end{array}$} \\
\hline & Group & Median & Male & Female & Male & Female & & \\
\hline KATS $^{*}(1979)$ & $0 \sim 2 \mathrm{mon}$ & $1 \mathrm{mon}$ & 55.1 & 54.2 & 4.9 & 4.7 & 1979 & 85 \\
\hline KATS(1996) & $0 \sim 3 \mathrm{mon}$ & $2 \mathrm{mon}$ & 57.3 & 56.6 & 5.1 & 5.0 & 1996 & 1,007 \\
\hline KATS(2004) & $0 \sim 3 \mathrm{mon}$ & $2 \mathrm{mon}$ & 59.1 & 57.4 & 5.9 & 5.2 & 2004 & 1,726 \\
\hline KATS(1979) & $20 \sim 24$ & 22 & 167.7 & 155.5 & 61.3 & 52.7 & 1958 & 0.9 \\
\hline KATS(1985) & $21 \sim 25$ & 23 & 167.7 & 155.4 & 60.8 & 51.2 & 1963 & 1.8 \\
\hline KATS(1996) & $20 \sim 24$ & 22 & 169.6 & 158.8 & 63.6 & 52.5 & 1964 & 2.6 \\
\hline MCST $^{* *}$ & $19 \sim 24$ & 22 & 169.9 & 157.9 & 62.4 & 52.1 & 1969 & 6.8 \\
\hline MCST & $19 \sim 24$ & 22 & 171 & 159.3 & 66.7 & 54.9 & 1972 & 13 \\
\hline KATS(1991) & $22 \sim 24$ & 23 & 171.3 & 160.2 & 65.6 & 51.7 & 1974 & 23 \\
\hline MCST & $19 \sim 24$ & 22 & 172.8 & 160 & 69.3 & 53.9 & 1975 & 29 \\
\hline KATS(1991) & $20 \sim 21$ & 20 & 170.8 & 160.6 & 63.7 & 52.2 & 1977 & 50 \\
\hline MCST & $19 \sim 24$ & 22 & 173.4 & 160.7 & 68 & 53.4 & 1978 & 67 \\
\hline MCST & $19 \sim 24$ & 22 & 173.7 & 161.4 & 68 & 53.6 & 1981 & 124 \\
\hline KATS(2004) & $20 \sim 24$ & 22 & 173.8 & 160.7 & 69.5 & 53.5 & 1983 & 164 \\
\hline MCST & $19 \sim 24$ & 22 & 173.5 & 161.6 & 71.3 & 53.6 & 1984 & 185 \\
\hline MCST & $19 \sim 24$ & 22 & 175 & 161.9 & 71.6 & 54.4 & 1987 & 280 \\
\hline MCST & $19 \sim 24$ & 22 & 174.1 & 161.5 & 71.5 & 55.2 & 1989 & 373 \\
\hline
\end{tabular}

*: data from corresponding year's report by Korea Agency for Technology and Standards;

**: data from home page of Ministry of Culture, Sports \& Tourism. 
령대가 출생한 시점의 것을 사용하였다. 예를 들어, 2004년 에 실시한 인체 측정 조사 사업의 20 24세 그룹의 경우, 출생 시점을 인체 측정 조사 시점에서 연령 그룹의 중앙값을 빼는 방식으로 1983년(2004 - 중앙값(22세) + 1)으로 추정하고, 1983 년 일인당 $\mathrm{GNP}$ 를 이 연령대의 소득으로 사 용하였다.

\section{Results}

\subsection{Data}

2. Methods에서 언급한 방법으로 구한 신장, 체중, 일인당 GNP 자료는 Table 1에 자료 출처, 연령대, 추정 출생 연도 와 함께 정리되어 있다.

\section{$3.220 s^{\prime}$ stature}

추정 출생 연도별 신장 추이는 Figure 1에 일인당 GNP 와 함께 나와 있다. 1977년 생 남자, 1969년 및 1983년 생 여자 자료를 제외하면 본 연구에서 제시한 신장 자료는 1958년부터 1987년까지 지속적으로 증가하다 마지막 해인 1989년에는 약간 감소하는 추세를 보였다. 이 기간 동안 신장이 남자는 $6.4 \mathrm{~cm}$, 여자는 $6.1 \mathrm{~cm}$ 증가하고, 소득은 약 414 배 증가하였다.

소득 수준이 10만원 이하로 매우 낮고 변동이 크지 않았 던 1950, 1960년대에는 1964년을 제외하고는 신장의 변화 가 거의 관찰되지 않았다. 소득 수준이 가파르게 상승하기 시작하는 1960년대 말, 1970년대 초부터 신장이 1987년 자료까지 완만하게 증가하는 추세를 보였다.

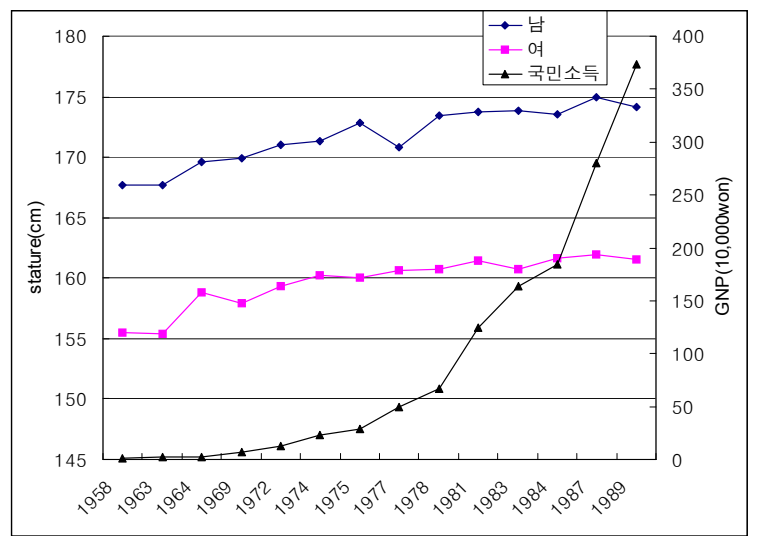

Figure 1. 20s' stature and GNP according to year

\subsection{Infants' stature}

0 2개월 영아에 대한 자료는 3개만 찾을 수 있었으며, Figure 2에 일인당 GNP 자료와 같이 연도별로 제시되어 있 다. 영아의 신장은 1979년에 비하여 2004년에 남아는 약 $4.0 \mathrm{~cm}(1979$ 년 자료 대비 $7.3 \%)$, 여아는 약 $3.2 \mathrm{~cm}(1979$ 년 자료 대비 $5.9 \%$ ) 증가하였다. Figure 2는 영아의 신장 이 소득 수준과 함께 거의 선형적으로 증가하였음을 보이고 있다.

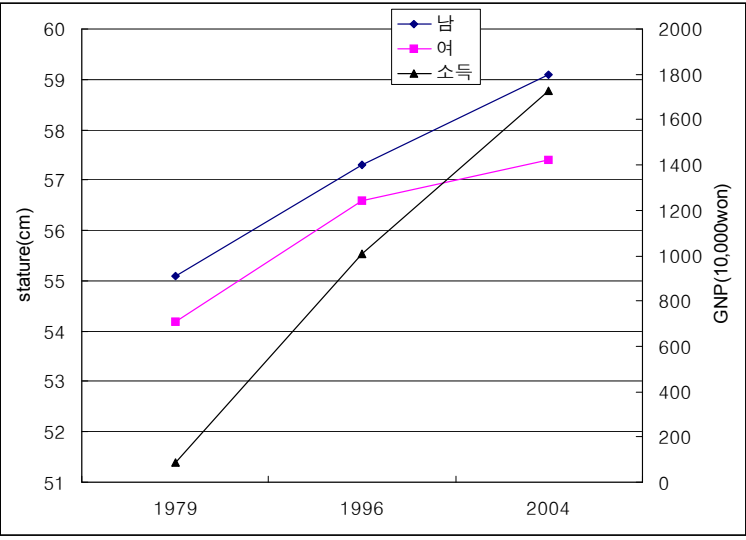

Figure 2. Infants' stature and GNP according to year

\subsection{0s' body weight}

추정 출생 연도별 20대 체중 자료는 Figure 3 에 나와 있 다. 남성의 체중 자료는 1978 년까지 약간의 부침(浮沈)이 있으나 전반적으로 연도에 따라 증가하는 추세를 보였다. 1978년 이후에는 감소 없이 증가 추세가 지속적으로 나타 났다. 여성의 경우는 1977 년 이전에는 뚜렷한 경향성을 발

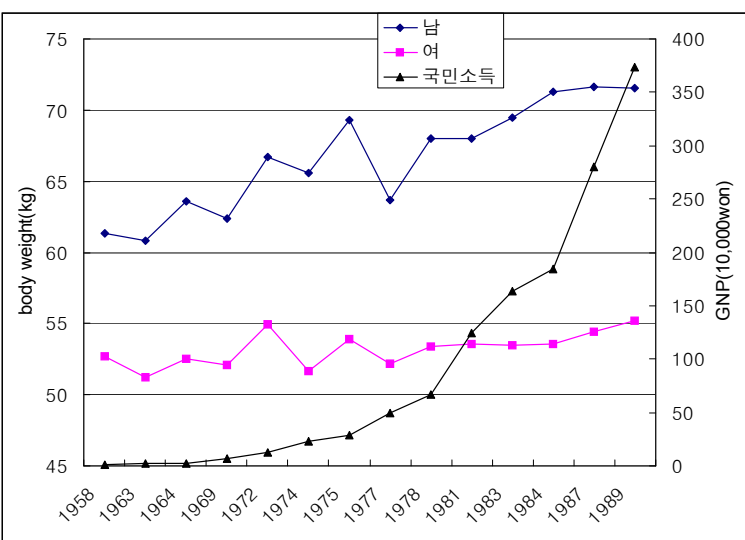

Figure 3. 20s' body weight and GNP according to year 
견하기 어려우나 1977 년부터는 완만하게 상승하는 추세를 보이고 있다. 자료 조사 기간에 남성은 약 $10.7 \mathrm{~kg}$, 여성은 약 $4.0 \mathrm{~kg}$ 의 체중이 증가하였다.

소득과의 관계를 살펴보면 남성은 소득이 증가함에 따라 체중이 증가하는 현상을 볼 수 있다. 그러나 여성은 1960년 대에는 변동은 있으나 증가 혹은 감소 추세를 보이지 않았으 나, 소득이 급격히 증가하는 1970년대 중 - 후반부터 체중이 아주 완만하게 증가하는 경향을 보이고 있다.

\subsection{Infants' body weight}

출생 연도 및 소득 수준에 따른 영아의 체중은 Figure 4 에 제시되어 있다. 영아의 체중은 출생 연도 및 소득 수준에 따라 거의 선형적으로 증가하는 추세를 보였다. 분석 기간 동 안 남아는 $1.0 \mathrm{~kg}$ (1979년 자료 대비 20.4\%), 여아는 $0.5 \mathrm{~kg}$ (1979년 자료 대비 10.6\%)의 체중 증가가 있었다.

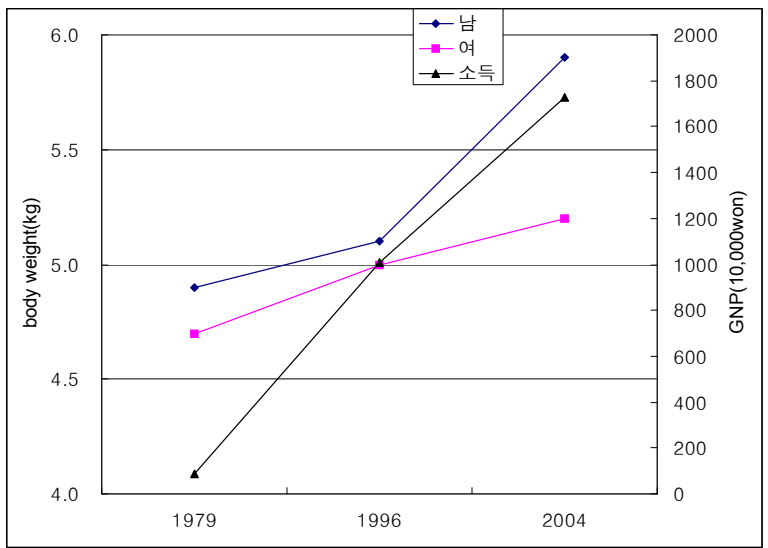

Figure 4. Infants' body weight and GNP according to year

\subsection{Correlation analysis}

신장, 체중과 소득 수준 간의 상관계수는 Table 2에 정리 되어 있다. 모든 상관계수가 0.66 이상으로 나타나 대표적 인체 측정치인 신장과 체중이 소득 수준과 높은 양의 상관 관계에 있음을 보였다. 20대 남자는 신장보다 체중이 소득

Table 2. Correlation coefficients between GNP and stature, body weight

\begin{tabular}{l|c|c|c|c}
\hline \multirow{2}{*}{} & \multicolumn{2}{|c|}{$20 \mathrm{~s}$} & \multicolumn{2}{c}{ Infant } \\
\cline { 2 - 5 } & Male & Female & Male & Female \\
\hline GNP and stature & 0.73 & 0.67 & 0.99 & 0.98 \\
\hline GNP and body weight & 0.80 & 0.66 & 0.92 & 0.99 \\
\hline
\end{tabular}

수준과의 상관계수가 높게 나타났으며, 여자의 경우는 신장 및 체중과 소득 수준 간의 상관계수가 차이를 보이지 않았다. 영아의 신장, 체중과 소득 수준 간의 상관계수는 1.0 에 가까 워 영아의 신장, 체중과 소득 수준은 매우 높은 상관 관계가 있음을 보였다.

\section{Discussion and Conclusions}

본 연구에서는 기술표준원의 한국인 인체 측정 조사와 문 화체육관광부의 자료를 이용하여 출생 연도 기준으로 1958 년부터 1989년(조사 시점 기준: 1979 2009년)까지의 신 장 및 체중과 소득 수준 간의 관계를 분석하였다. 연구 결과 소득 수준이 증가함에 따라 신장 및 체중이 증가하는 경향을 보였다. 특히, 신장은 소득의 증가 경향이 뚜렷이 나타나는 1960년 중 - 후반부터 증가 추세가 눈에 띄게 나타났다. 소 득 증가에 따른 체중의 증가 현상은 여성보다 남성에서 크게 나타났다. 영아의 경우는 신장, 체중 모두 소득 수준과 거의 선형적 관계로 증가하는 경향을 보였다. 그러나 분석에 사용 된 자료가 소수(3개)여서 해석 시 주의가 요망된다. 이러한 본 연구는 식민지 시대의 신장 변화와 생활 수준 간의 관계 를 분석한 Choi(2006)의 연구에 비하여, 경제가 비약적으 로 성장한 시기의 인체 측정치와 소득 수준 간의 관계를 다 룬 점에 의의가 있다 하겠다.

분석 기간 동안 신장의 경우 남성 약 $6.4 \mathrm{~cm}$ (최소치 (1958년) 자료 대비 약 $3.8 \%$ ), 여성 $6.1 \mathrm{~cm}$ (최소치(1958 년) 자료 대비 약 $3.9 \%$ ) 증가하여 남녀가 비슷한 증가량을 보였다. 반면, 체중의 경우는 남성 약 $10.7 \mathrm{~kg}$ (최소치(1963 년) 대비 약 $17.6 \%$ ), 여성 $4.0 \mathrm{~kg}$ (최소치(1963년) 대비 약 $7.8 \%$ ) 증가하여 남녀의 증가량 및 증가율에 큰 차이를 보였 다. 이는 신장은 소득 수준 이외에 유전적 요인의 영향을 많 이 받아 생물학적 한계가 있기 때문에, 성내 및 성별 간 변 동이 크지 않게 나타난 것이라 할 수 있다. 체중은 신장보다 는 생물학적 한계의 범위가 커 소득 수준에 따른 변동량이 컸다고 볼 수 있다. 또한, 남성에 비하여 여성의 체중 변화량 이 작은 것은 소득 수준, 유전적 요인의 영향과 더불어 남성 보다 다이어트를 통한 신체적 아름다움에 대한 관심이 높기 때문인 것으로 해석된다.

\section{References}

Choi, S.J., Variations of stature and standard of living for Korean-focused 
on Japan-governed era, Unpublished master thesis, Faculty of Economics, Seoul National University, 2006.

Jung, B.Y., Anthropometric study of physical growth in height, Journal of the Ergonomics of Korea, 17(3), 91-101, 1998.

Jung, S-G. and Lee, S-D., A study on anthropometric measurement and type classification of foot for the elderly, Journal of Korean Society of Design Science, 14(2), 95-105, 2001.

Kee, D., Lee, G.T., Park, J.H. and Choi, K.I., Ergonomics, Hankyungsa, 2011.

Kim, J.H., Oark, S.C., Chang, M.H. and Kim, C.J., A study on anthropometric survey in Korea, Journal of the Ergonomics of Korea, 8(1), 19-29, 1989.

KOSIS(Korean Statistical Information Service) Home Page, http://kosis.kr/ (retrieved December 20, 2011).

Kroemer, K. H. E, Kroemer, H. B. and Kroemer-Elbert, K. E., Ergonomics: How to design for ease and efficiency, Prentice Hall, 1994.

Tanner, J. M., Physical growth from conception to maturity, Cambridge, Mass., 1978.

Size Korea Home Page, http://sizekorea.kats.go.kr/(retrieved December 20, 2011).

Yoo, J-W., A study for the characteristics of Korean body size along with the age and sex, Journal of the Ergonomics of Korea, 25(2), 71-76, 2006.

\section{Author listings}

Dohyung Kee: dhkee@kmu.ac.kr

Highest degree: PhD, Department of Industrial Engineering, POSTECH Position title: Professor, Department of Industrial and Management Engineering, Keimyung University

Areas of interest: Musculoskeletal disorders, Population stereotype, Postural stress, Industrial safety

Date Received : 2011-12-31

Date Revised :2012-01-19

Date Accepted : 2012-01-19 